\title{
An Analysis of Presentation, Pattern and Outcome of Chest Trauma Patients at an Urban Level 1 Trauma Center
}

\author{
Rajasekhar Narayanan $^{1}$ - Subodh Kumar ${ }^{1}$ - Amit Gupta ${ }^{1}$ - Virinder Kumar Bansal ${ }^{1}$. \\ Sushma Sagar ${ }^{1}$ - Maneesh Singhal ${ }^{1}$ • Biplab Mishra ${ }^{1} \cdot$ Sanjeev Bhoi ${ }^{2} \cdot$ Babita Gupta $^{3}$. \\ Shivanand Gamangatti ${ }^{4}$. Adarsh Kumar $^{5}$ - Mahesh Chandra Misra ${ }^{1}$
}

Received: 28 July 2016 / Accepted: 7 October 2016 /Published online: 19 October 2016

(C) Association of Surgeons of India 2016

\begin{abstract}
Chest trauma is an important public health problem accounting for a substantial proportion of all trauma admissions and deaths. It directly account for $20-25 \%$ of deaths due to trauma. Therefore, this study was conducted to analyze the presentation, patterns, and outcome of chest trauma in a level1 urban trauma center. It was a prospective observational study of all patients presented with chest trauma to an urban level 1-trauma center over a period of 3 years. Demographic profile, mechanism of injury, injury severity scores (ISS), associated injuries, hospital stay, etc. were recorded. Morbidity and mortality rates were analyzed and compared with the published literature. Chest injuries comprised $30.9 \%$ of all trauma admissions and the mechanism was blunt in majority $(83.5 \%)$
\end{abstract}

of the cases. Vehicular crashes $(59.7 \%)$ followed by assault were the most common modes of injury. Rib fracture was the most common chest injury seen in 724 of the 1258 patients while abdominal visceral injuries were the commonest associated injuries in polytrauma cases. Majority of the patients were managed non-operatively. Inter costal tube drainage (ICD) was the main stay of treatment in $75 \%$ of the cases, whereas, thoracotomy was required only in $5.56 \%$ of the patients. Overall mortality was $11 \%$ and it was found to be significantly higher following blunt chest trauma. We observed that associated extra thoracic injuries resulted in higher mortality as compared to isolated chest injuries. Thoracic injuries can be readily diagnosed in the emergency department

\author{
Subodh Kumar \\ subodh6@gmail.com \\ Rajasekhar Narayanan \\ nrajasekhar82@gmail.com \\ Amit Gupta \\ amitguptaaiims@gmail.com \\ Virinder Kumar Bansal \\ drvkbansal@gmail.com \\ Sushma Sagar \\ sagar.sushma@gmail.com \\ Maneesh Singhal \\ drmaneesh@gmail.com \\ Biplab Mishra \\ biplabaiims@gmail.com \\ Sanjeev Bhoi \\ sanjeevbhoi@gmail.com \\ Babita Gupta \\ drbabitagupta@yahoo.co.in
}

\author{
Shivanand Gamangatti \\ shiv223@rediffmail.com \\ Adarsh Kumar \\ dradarshk@yahoo.com \\ Mahesh Chandra Misra \\ mcmisra@gmail.com
}

1 Department of Surgery, JPN Apex Trauma Center, All India Institute of Medical Sciences, New Delhi 110029, India

2 Department of Emergency Medicine, JPN Apex Trauma Center, All India Institute of Medical Sciences, New Delhi 110029, India

3 Department of Anesthesia, JPN Apex Trauma Center, All India Institute of Medical Sciences, New Delhi 110029, India

4 Department of Radiodiagnosis, JPN Apex Trauma Center, All India Institute of Medical Sciences, New Delhi 110029, India

5 Department of Forensic Medicine, JPN Apex Trauma Centre, All India Institute of Medical Sciences, New Delhi 110029, India 
by meticulous and repeated clinical evaluation and majority require simple surgical procedures to prevent immediate mortality and long-term morbidity.

Keywords Chest trauma · Thoracotomy · Blunt thoracic injury $\cdot$ Penetrating thoracic injury

\section{Introduction}

Thoracic trauma is a significant cause of mortality. Many patients with these injuries die after reaching the hospital. However, many of these deaths could be prevented with prompt diagnosis and treatment. Less than $10 \%$ of blunt chest injuries and only 15 to $30 \%$ of penetrating chest injuries require operative intervention [1]. In fact, most patients who sustain thoracic trauma can be treated by simple emergency room (ER) procedures, which are within the capabilities of most of the emergency healthcare workers [1]. Chest injuries contribute to around $10 \%$ of total trauma-related deaths and $15 \%$ of loss of disability adjusted life years (DALYS) and they are the second leading cause of death in pediatric trauma [2]. Due to scarcity of data, true magnitude of chest injury along with its complications cannot be assessed. Analysis and interpretation becomes difficult, thereby defying effective counter measures, evaluations, and strategies for prevention of these injuries. Therefore, this study was designed to analyze the magnitude, severity, and outcome of chest trauma received and managed at a level-1 trauma center in urban India.

\section{Material and Methods}

This prospective observational study was conducted to include all consecutive chest trauma patients admitted in Division of Trauma Surgery and Critical Care at JPN apex Trauma Centre (JPNATC), All India Institute of Medical Sciences from January
2012 through December 2014. Patients who were brought in state of cardiac arrest or found dead were excluded from the study. A detailed evaluation of all the cases was done which included primary and secondary survey, radiological investigations, biochemical parameters, and emergency room procedures. All thoracic as well as associated injuries were adequately addressed and documented carefully in a prestructured form. All these patients were followed up for a period of 30 days to study morbidity and mortality. Ethical clearance was obtained from the Institutional Ethics committee.

Statistical analysis of the data collected was done using descriptive statistics such as mean, median, and mode and multivariate analysis for study of outcome. Quantitative data was analyzed using Student's $t$ test and qualitative data with chi-square test. Confidence interval of $95 \%$ with $p$ value of $<0.05$ was taken as statistically significant.

\section{Results}

Of all trauma admissions, chest injuries were present in $30.9 \%$ of patients. A total of 1258 patients with chest trauma presented to JPNATC during the study. There was male preponderance (M:F; $8: 1$ ). Mean age of patients was 37.82 years (range 3 years to 86 years). Majority of patients were in age group of 18-65 years $(86 \%)$. Majority of patients $(71 \%)$ were brought by relatives followed by police $(23 \%)$ and the rest were brought by bystanders. Predominant mechanism of injury was blunt trauma seen in $83.5 \%$, whereas, the remaining $16.5 \%$ patients sustained penetrating chest trauma. The most common mode of injury was road traffic injuries (RTI) in $751(59.7 \%)$ patients. Among patients of RTI, $35 \%$ cases were involved in motorized two wheeler crashes, $30 \%$ patients had four wheeler related injuries, $5 \%$ sustained bicycle related injuries, and the remaining $30 \%$ victims were pedestrians hit by moving vehicles. Out of 290 patients who presented with history of assault, $42 \%$ sustained stab injuries, $49 \%$ patients sustained gunshot injuries, and the remaining $8 \%$

Fig. 1 Pattern of chest injuries

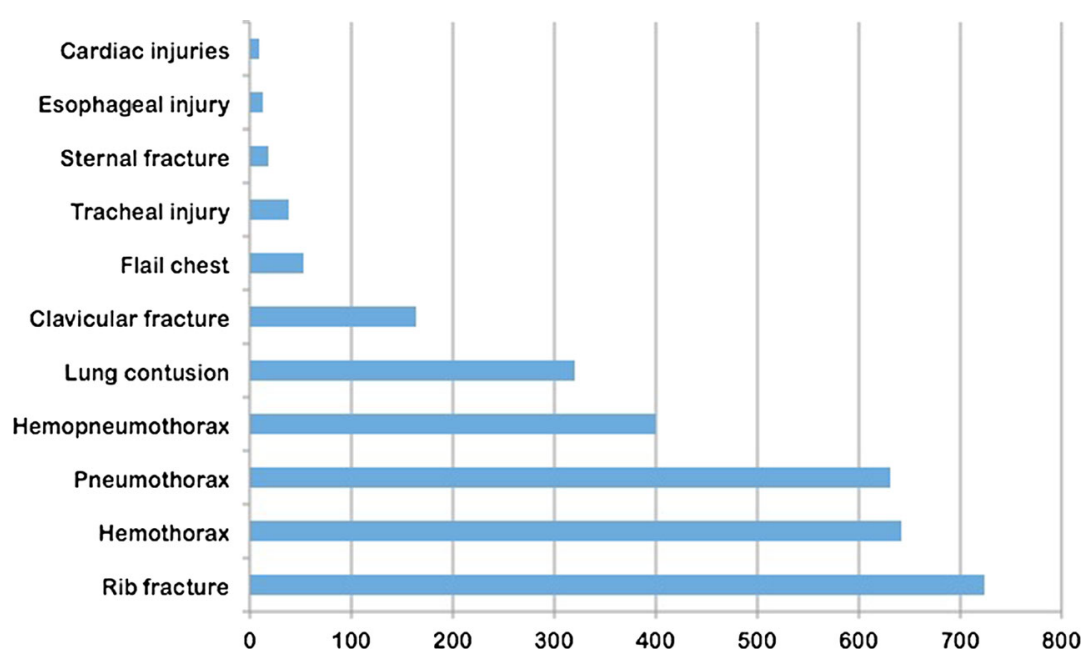


Table 1 Indications for emergency thoracotomy

\begin{tabular}{lc}
\hline Indications & No. of patients \\
\hline ED thoracotomy & $6(8.58 \%)$ \\
Lung laceration & $24(34.29 \%)$ \\
Right ventricular injury & $9(12.86 \%)$ \\
Right atrial injury & $8(11.42 \%)$ \\
Aortic injury & $6(8.58 \%)$ \\
Subclavian vessel injury & $11(15.71 \%)$ \\
Penetrating chest injury & $2(2.85 \%)$ \\
Diaphragmatic injury & $4(5.72 \%)$ \\
\hline
\end{tabular}

were assaulted with iron rods or other heavy objects. Other mechanisms included animal related injuries and railway track injuries.

Only $10 \%$ patients were brought within the "Golden Hour" and majority could reach within $6 \mathrm{~h}$ of injury. Out of $1258 \mathrm{pa}-$ tients, 955 (75.92\%) patients were hemodynamically stable and $303(24.08 \%)$ patients were hemodynamically unstable at presentation. Out of 303 hemodynamically unstable patients, 164 $(54.12 \%)$ patients were responders who became hemodynamically stable after initial resuscitation. There were $73(24.10 \%)$ transient responders and $66(21.78 \%)$ non-responders. Isolated chest injuries were present in $468(37.2 \%)$ patients and the remaining $790(62.8 \%)$ patients were diagnosed as polytrauma cases. At presentation, chest compression test (CCT) was found to be positive in $846(67.25 \%)$ patients and subcutaneous emphysema was present in $40 \%$ patients.

Rib fractures were the most frequent injury either as isolated injury ( 82 patients) or associated with other thoracic or extra thoracic injuries (37 patients). Next common injuries were hemothorax and pneumothorax (Fig. 1). Esophageal and cardiac injuries were least common (Fig. 1). Needle thoracostomy was done in 9 patients in the ER for tension pneumothorax. Cardiac injuries were diagnosed in $17(1.35 \%)$ patients (11 blunt trauma,

Table 2 Morbidity

\begin{tabular}{ll}
\hline Complications & Incidence \\
\hline Ventilator associated pneumonia, sepsis, & $2.94 \%$ \\
$\quad$ Multiorgan dysfunction syndrome & $2.38 \%$ \\
Fever, pneumonia & $1.74 \%$ \\
Retained hemothorax & $1.43 \%$ \\
Wound infection & $1.19 \%$ \\
Empyema & $0.6 \%$ \\
Delayed pleural effusion & $0.9 \%$ \\
Delayed pneumothorax & $0.2 \%$ \\
Acute Renal failure & $0.5 \%$ \\
Acute pulmonary embolism & $0.23 \%$ \\
Pressure ulcer & $0.5 \%$ \\
\hline
\end{tabular}

Table 3 Causes of death

\begin{tabular}{ll}
\hline Causes of death & Percentage of patients \\
\hline Hemorrhagic shock & $50 \%$ \\
Sepsis, MODS & $24.65 \%$ \\
Cardiac failure & $7.25 \%$ \\
DIC & $3.62 \%$ \\
Respiratory failure & $3.62 \%$ \\
Acute pulmonary embolism & $3.62 \%$ \\
Severe abdominal injury & $3.62 \%$ \\
Head injury & $3.62 \%$ \\
\hline
\end{tabular}

6 penetrating trauma). Focused assessment sonography in trauma (FAST) examination showed pericardial effusion in 14 cases and pericardiocentesis was done in all of them. Intraoperatively, 9 patients were found to have rupture of right ventricle and rupture of the right atrium was found in 8 patients. Ten patients survived cardiac injury and discharged in a stable condition. Seven patients with cardiac injuries died either in operating room (OR) or postoperatively in intensive care unit (ICU). Among major vessels, aorta was injured in 6 cases and subclavian vessels were injured in 11 cases. Esophageal injury was diagnosed in 6 patients and diaphragmatic injury was present in 33 patients.

Overall, mean ISS was $15.63 \pm 8.85$ with a median of 13 . Mean ISS was $16.6 \pm 7.4$ in blunt trauma, $14.7 \pm 5.9$ in penetrating trauma, and $18.0 \pm 5.5$ in polytrauma cases. The mean new injury severity score (NISS) was $19.31 \pm 9.53$ with a median of 19 .

The most common surgical procedure was ICD insertion and was carried out in 948 (75.35\%) patients (unilaterally in $81 \%$ and bilaterally in $19 \%$ ). Among 468 patients with isolated chest injuries, $72 \%$ patients required ICD insertion. The mean duration of ICD was $6.94 \pm 4.21$ days with a median of 6 days (range 1-32 days). Eighty-seven percent of patients with hemothorax required ICD insertion, whereas, $95 \%$ cases of pneumothorax, $98 \%$ patients with hemopneumothorax, and $85 \%$ cases with pulmonary contusion required ICD insertion. Tracheostomy was done in $131(10.41 \%)$ patients for two main indications - prolonged ventilation and tracheal injury. Two hundred and six (16.45\%) patients were shifted directly to OR either for thoracotomy or for laparotomy for associated injuries and $306(24.3 \%)$ patients were directly shifted to ICU from ED after initial emergency management.

Table 4 Outcome analysis

\begin{tabular}{llll}
\hline Parameter & Blunt injury & Penetrating injury & $P$ value \\
\hline Mortality rate & $11.65 \%$ & $5.63 \%$ & 0.001 \\
Injury severity score & $16.6 \pm 7.4$ & $12.7 \pm 2.9$ & NS \\
Hospital stay (days) & 10.09 & 10.07 & NS \\
Morbidity & $22.18 \%$ & $22.53 \%$ & NS \\
\hline
\end{tabular}


Emergency thoracotomy was done in 70 (5.56\%) patients (Table 1). Resuscitative ER thoracotomy was done in 6 patients who presented in a state of shock or pulseless electrical activity (PEA) following isolated penetrating chest injury with pericardial tamponade. Video-assisted thoracoscopic surgery (VATS) was done in 12 cases for various indications like removal of bullet from mediastinum or thorax and for suspected diaphragmatic hernia. Epidural analgesia was given in 392 $(31.2 \%)$ patients.

Morbidity in both blunt and penetrating injury groups was similar (22.18 and $22.53 \%$, respectively). Overall, 280 $(22.25 \%)$ patients developed some complications and out of which, $55(11.75 \%)$ patients had isolated chest injuries (Table 2). Overall, the mean ICU stay was 7.31 days \pm 6.3 and median of 5 days (range 0 to 35 days). Mean hospital stay was $10.09 \pm 8.18$ days with a median of 8 days (range 0 to 68 days).

There were $138(11 \%)$ deaths. Mortality rate in blunt thoracic trauma group was $11.65 \%(n=122)$ higher as compared to penetrating trauma group $7.69 \%(n=16)$. Deaths were significantly associated with advancing age as was evident by 75 deaths $(24 \%)$ in geriatric (age $>60$ years) age group. Mortality among postoperative patients was $28.88 \%(n=41)$. Three cases expired due to mediastinitis and sepsis following esophageal injuries. Number of deaths within $6 \mathrm{~h}$ of admission were $24(17.39 \%)$, within $24 \mathrm{~h}$ were $78(56.52 \%)$, within $72 \mathrm{~h}$ were $113(81.88 \%)$, and after $72 \mathrm{~h}$ of admission were 25 $(18.12 \%)$. The cause of death in immediate and early group was severe hemorrhagic shock (Table 3). The difference in the mortality rates between blunt and penetrating injury groups was statistically significant (Table 4).

\section{Discussion}

A thorough review of literature suggests that the road traffic crashes are the leading cause of chest trauma in most series [3-5]. Scenario is no different in India which is accounting for almost $6 \%$ of global vehicular crashes [4]. In the present study also, RTI was responsible for the injury in the majority and second most common mode of injury was assault. In our study, we observed some mechanism of injuries which are peculiar to developing nations like ours, especially in rural India, such as assault by animals, agriculture-related injuries, and railway tract injuries. In India, animals are frequently used for agricultural and transport purposes resulting in distinct pattern of injuries including chest trauma. Railway tracks are routinely crossed by pedestrians as trespassers and they sustain various injuries from moving trains.

In our study, associated injuries $(62.8 \%)$ were comparable to the published literature. Abdominal visceral injuries was the most common associated injury $(24.88 \%)$ which is in contrast to the available literature wherein head injury has been described as the most common associated injury [4, 6]. Other commonly associated injuries were extremity fractures followed by pelvic fracture, head injury, spine injury, and maxillofacial. Shorr and colleagues found associated injuries in more than $75 \%$ of thoracic trauma patients [7]. In a nationwide ER survey in UK, Elisabeth et al. observed that the number of rib fractures and associated injuries were associated with morbidity and mortality in $27.8 \%$ of the patients with blunt chest trauma [8].

A review of data from the trauma registry at University Hospital in San Antonio indicated that 1722 (27\%) of 6332 patients with multiple traumatic injuries and an Injury Severity Score (ISS) of 15 or higher had pulmonary contusions. Pulmonary contusion is the most common pulmonary parenchymal injury in blunt chest trauma [9].

We observed that $51 \%$ of patients had hemothorax in our study and $63 \%$ of them were associated with rib fracture. This is consistent with the available data in literature [9, 10]. In our study, rib fractures were the most common injury which is in accordance with the published literature [9, 11, 12]. Kulshrestha et al. found an incidence of 1.5 to $6 \%$ of cardiac injuries among chest trauma patients in a single unit [13]. We also observed cardiac injuries in $1.35 \%$ of cases and great vessel injuries in $1.35 \%$ cases.

Majority of our patients with chest injuries were managed non-operatively which is in agreement with other studies [12-15]. Tube thoracostomy was the mainstay of treatment for the majority $(75.35 \%)$ of patients. The role of prophylactic antibiotics in tube thoracostomy remains a debatable issue but our institutional policy is to administer a single dose of broad spectrum parenteral antibiotic prior to ICD insertion. A recent meta-analysis has concluded that prophylactic antibiotic treatment reduces the risk of developing infectious complications after tube thoracostomy for traumatic injuries of the chest, with the effect best documented for penetrating injuries [16]. The incidence of posttraumatic empyema has been reported in the range of 2 to $25 \%$ with Staphylococcus aureus being the most common organism $[17,18]$.

Mechanical ventilation was required in $18.68 \%$ of patients. Emergency thoracotomy was performed in $5.24 \%$ of patients. These figures are similar to the published literature [5, 8-10]. Richardson observed that less than $5 \%$ of patients sustaining blunt chest trauma had indications for thoracotomy [19]. Average duration of chest tube was 4.5 days in a study by Locurto et al. [20]. In our series, the mean duration of ICD was 6.94 days. The mean ICU stay in our study was 7.31 days and the mean hospital stay was 10.09 days in comparison to mean ICU stay of 4.5 days in a study by Veysi et al. [4]. The increased length of ICU stay was probably due to severity of chest injury and associated injuries in our series.

Mortality rate is variable among different authors, ranging from 6.6 to $18.7 \%$ [4, 8-10, 21, 22]. In a study by Acosta et al., mortality rate was $9.3 \%$ and respiratory failure was the most common reason for mortality [23]. The overall morbidity rate 
in the management of chest trauma in the same series was $25.8 \%$ and the study concluded that atelectasis was the most common morbidity, with an incidence of $14.6 \%$. Other significant causes of morbidity among chest injury patients include empyema and lung abscess. Residual hemothorax was the commonest complication as mentioned by Thomas et al. [24]. Griffith et al. found overall morbidity rate of $25.8 \%$ in the management of chest trauma wherein atelectasis was the most common entity in $14.6 \%$ cases [6]. The incidence of empyema in our series was $0.6 \%$. Overall morbidity in our series was $22.25 \%$. Pyrexia and pneumonia were the most common morbidity $(2.38 \%)$. Ventilator-associated pneumonia (VAP) is also a common occurrence in patients who are mechanically ventilated for a prolonged period. Our institutional policy is to have a strict surveillance by infection control team and to perform tracheostomy relatively early wherever feasible and whenever ventilator support is expected beyond 1 week.

Hemorrhagic shock was the second most frequent cause of death in trauma patients and was the leading cause of early inhospital trauma deaths in various reviews $[4,25,26]$. In our series, the mortality rate was $11 \%$ and the most common cause of in-hospital death was hemorrhagic shock (50\%). In a recent study by Lema et al., the overall mortality rate was $4.7 \%$, which is relatively lower than that reported in other studies in the literature [27]. Hospital mortality rates for isolated chest injuries were reported to range from 4 to $8 \%$ and increased to 13-15\% when another organ system was involved and to 30-35\% when more than one organ system was involved [26, 27]. Lee et al. reported the mortality rate as $1.8 \%$ in all patients with blunt chest trauma [28]. In a systematic review and meta analysis by Battle et al., the three major risk factors for mortality in blunt trauma chest were age more than 65 years, three or more rib fractures and presence of preexisting disease, especially cardiopulmonary disease [26]. It is quite evident from various studies that elderly population has a higher mortality and morbidity following thoracic injuries when compared to younger age groups [25, 26, 29, 30].

\section{Conclusions}

Chest trauma occurs in a significant number of trauma patients and commonly affects young males of productive age group. This study emphasizes and highlights the fact that more than $90 \%$ of the chest injuries can be effectively managed with careful initial assessment and simple emergency surgical procedures. With thorough clinical examination, relevant investigations, close monitoring, pain relief, aggressive chest physiotherapy, timely referral, and appropriate management, most of the serious chest injuries as well as associated injuries can be managed successfully. Multidisciplinary approach in the management of these patients, especially in extreme age groups, is life saving and decreases the antecedent morbidity and mortality.

\section{Compliance with Ethical Standards}

Funding No funding received from any source.

Ethical Approval Obtained from the Institutional Ethics Committee.

Conflict of Interest Rajasekhar Narayanan, Subodh Kumar, Amit Gupta, Virinder Kumar Bansal, Sushma Sagar, Maneesh Singhal, Biplab Mishra, Sanjeev Bhoi, Babita Gupta, Shivanand Gamangatti, Adarsh Kumar, and Mahesh Chandra Misra do not have any conflict of interest.

\section{References}

1. LoCicero J 3rd, Mattox KL (1989) Epidemiology of chest trauma. Surg Clin North Am 69:15-19

2. Joshi R, Cardona M, Iyengar S, Sukumar A, Raju CR, Raju KR, Raju K, Reddy KS, Lopez A, Neal B (2006) Chronic diseases now a leading cause of death in rural India - mortality data from Andhra Pradesh Rural Health Initiative. Int J Epidemiol 35:1522-1529

3. Nakayama DK, Ramenofsky ML, Rowes MI (1989) Chest injuries in childhood. Ann Surg 210:770-775

4. Veysi VT, Nikolaou VS, Paliobeis C, Efstathopoulos N, Giannoudis PV (2009) Prevalence of chest trauma, associated injuries and mortality - a level 1 trauma centre experience. Int Orthopaedics 33: $1425-1433$

5. Karmy-Jones R, Jurkovich GJ, Brundage S, Wall MJ Jr, Engelhardt S, Hoyt DB, Holcroft J, Knudson MM (2001) Timing of urgent thoracotomy for hemorrhage after trauma: a multicenter study. Arch Surg 136:513-518

6. Pearson FG, Joel O, Deslauriers CJ, Ginsberg RJ, Hiebert C, Patterson GA, Urschel HC (2002) Thoracic surgery, 2nd edn. Churchill livingstone, London

7. Shorr RM, Crittenden M, Indeck M, Hartunian SL, Rodriguez A (1987) Blunt thoracic trauma - analysis of 515 patients. Ann Surg 206:200-205

8. Battle CE, Haylay H, Philip AE (2013) Expert opinion of the risk factor for morbidity and mortality in blunt chest wall trauma: result of an ED survey in UK. Injury 44:56-59

9. Cohn SM, Dubose JJ (2010) Pulmonary contusion -an update on recent advances in clinical management. World J Surg 34:1959-1970

10. Al-Koudmani, Darwish B, Al-Kateb K, Taifour Y (2012) Chest trauma experience over eleven-year period at al-mouassat university teaching hospital-Damascus: a retrospective review of 888 cases. J Cardiothorac Surg 7:35

11. Peterson RJ, Tepas JJ 3rd, Edwards FH, Kissoon N, Pieper P, Ceitham EL (1994) Pediatric and adult thoracic trauma: age-related impact on presentation and outcome. Ann Thorac Surg 58:14-18

12. Liman ST, Kuzucu A, Tastepe AI, Ulasan GN, Topcu S (2003) Chest injury due to blunt trauma. Eur J Cardiothorac Surg 23: 374-378

13. Kulshrestha P, Das B, Iyer KS, Sampath KA, Sharma ML, Rao IM, Venugopal P (1990) Cardiac injuries: a clinical and autopsy profile. J Trauma 30:203-207

14. Pate JW, Fabian TC, Walker W (1995) Traumatic rupture of the aortic isthmus: an emergency? World J Surg 19:119-126

15. Williams JS, Graff JA, Uku JM, Steinig JP (1994) Aortic injury in vehicular trauma. Ann Thorac Surg 57:726-730

16. Sanabria A, Valdivieso E, Gomez G, Echeverry G (2006) Prophylactic antibiotics in chest trauma: a meta-analysis of highquality studies. World J Surg 30:1843-1847 
17. Eren S, Esme H, Sehitogullari A, Durkan A (2008) The risk factors and management of posttraumatic empyema in trauma patients. Injury 39:44-49

18. Hoth JJ, Burch PT, Bullock TK, Cheadle WG, Richardson JD (2003) Prophylactic antibiotics adversely affect nosocomial pneumonia in trauma patients. Surg Infect 4:29-35

19. Richardson JD (1985) Indications for thoracotomy in thoracic trauma. Curr Surg 42:361-364

20. Locurto JJ Jr, Tischler CD, Swan KG, Rocko JM, Blackwood JM, Griffin CC, Lazaro EJ, Reiner DS (1986) Tube thoracostomy and trauma - antibiotics or not? J Trauma 26:1067-1072

21. Dalal S, Nityasha, Vashisht MG, Dahiya RS (2009) Prevalence of chest trauma at an apex institute of North India: a retrospective study. The Internet Journal of Surgery 18:1-5 http://print.ispub. com/api/0/ispub-article/5111

22. Demirhan R, Onan B, Oz K, Halezeroglu S (2009) Comprehensive analysis of 4205 patients with chest trauma: a 10 year experience. Interact Cardiovasc Surg 9:450-453

23. Acosta JA, Yang JC, Winchell RJ, Simons RK, Fortlage DA, Hollingsworth-Fridlund P, Hoyt DB (1998) Lethal injuries and time to death in a level I trauma center. J Am Coll Surg 186:528-533
24. shields TW, LoCicero J, Ponn RB (2000) General thoracic surgery, 5th edn. Lippincott Williams and Wilkins, Philadelphia

25. Lema MK, Chalya PL, Mabula JB, Mahalu W (2011) Pattern and outcome of chest injuries at Bugando Medical Centre in Northwestern Tanzania. J Cardiothorac Surg 6:7

26. Battle CE, Hutchings H, Evans PA (2012) Risk factors that predict mortality in patients with blunt chest wall trauma: a systematic review and meta-analysis. Injury 43:8-17

27. El-Menyar A, Abdelrahman H, Al-Hassani A, Ellabib M, Asim M, Zarour A, Al-Thani H (2016) Clinical presentation and time-based mortality in patients with chest injuries associated with road traffic accidents. Arch Trauma Res 5:e31888. doi:10.5812/atr.31888

28. Lee RB, Bass SM, Morris JA, MacKenzie EJ (1990) Three or more rib fractures as an indicator for transfer to a level I center: a population-based study. J Trauma 30:689-694

29. Bergeron E, Lavoie A, Clas D, Moore L, Ratte S, Tetreault S, Lemaire J, Martin M (2003) Elderly trauma patients with rib fractures are at greater risk of death and pneumonia. J Trauma 54:478-485

30. Morley EJ, Johnson S, Leibner E, Shahid J (2016) Emergency department evaluation and management of blunt chest and lung trauma (Trauma CME). Emerg Med Pract 18:1-20 